\title{
Cognitive and Functional Impairment in Stroke Survivors with Basilar Artery Occlusive Disease
}

\author{
Kenia Repiso Campanholo, ${ }^{1,2}$ Adriana Bastos Conforto, ${ }^{1,2}$ \\ Carolina Medeiros Rimkus, ${ }^{3}$ and Eliane Correa Miotto ${ }^{1,2}$ \\ ${ }^{1}$ Department of Neurology, University of São Paulo, 05403-000 São Paulo, SP, Brazil \\ ${ }^{2}$ Stroke Clinic, Department of Neurology, University of São Paulo, 05403-000 São Paulo, SP, Brazil \\ ${ }^{3}$ Department of Radiology, University of São Paulo, 05403-000 São Paulo, SP, Brazil \\ Correspondence should be addressed to Eliane Correa Miotto; ecmiotto@usp.br
}

Received 24 February 2015; Revised 14 May 2015; Accepted 26 May 2015

Academic Editor: Olivier Piguet

Copyright (c) 2015 Kenia Repiso Campanholo et al. This is an open access article distributed under the Creative Commons Attribution License, which permits unrestricted use, distribution, and reproduction in any medium, provided the original work is properly cited.

\begin{abstract}
Background. Despite growing literature on posterior vascular disease, specific information about the cognitive and functional profiles of patients with basilar artery occlusion disease (BAOD) is scarce. The aims of this study were (1) to compare the cognitive statuses of BAOD survivors versus healthy controls and (2) to correlate the functional capacity outcomes with the cognitive profiles of BAOD patients. Methods. Comprehensive cognitive and functional assessments were carried out in 28 patients with BAOD and 27 age- and education level-matched healthy controls. Results. Compared to matched controls, patients presented impairments in selective, sustained, and set-shifting attention, processing speed, visuospatial skills, mental flexibility, and monitoring rules. There were significant deficits in verbal episodic memory (immediate and delayed recall) and visuospatial episodic memory (immediate and delayed recall and recognition). Functional capacity outcomes were significantly related to the cognitive test results. Seventyfive percent of patients had a Modified Rankin Scale score of 0 or 1. Conclusions. Our results indicate good functional outcomes in a selected group of BAOD survivors, despite the presence of subnormal performance on some cognitive tests, including tests of attention, executive function, and long-term memory.
\end{abstract}

\section{Introduction}

Among all cases of stroke, $80 \%$ are ischemic, and $25 \%$ of infarcts are located in the vertebrobasilar arterial territory $[1,2]$. Reports of cognitive assessment in patients with vertebrobasilar infarcts are scarce and include patients with heterogeneous arterial lesions [3-5]. Poor performance can be detected across numerous cognitive domains, such as executive function, attention, memory [6], visuospatial function $[6,7]$, and language $[6,8]$. In particular, patients with infarcts in the basilar artery (BA) territory can present with impairments in executive function and episodic memory [4]. These cognitive deficits have been attributed to involvement of neural networks in the brainstem, cerebellum, and upper cortex [5]. Despite these cognitive deficits, good functional outcomes have been reported in up to $78 \%$ of survivors at 6 months $[9,10]$ and 1 year [11] after stroke, probably due to preservation of the eloquent cerebral regions. Functionality and quality of life were favorable in approximately $75 \%$ of basilar artery occlusion disease (BAOD) survivors at 4.2 years after stroke [12].

Previous studies have not considered the relationship between neuropsychological testing outcomes and functionality scales. Until now, specific information about the cognitive and functional profiles of BAOD patients has not been known. Therefore, the aims of this preliminary study were (1) to compare the cognitive statuses of BAOD survivors versus age- and education level-matched controls and (2) to correlate functional capacity outcomes with cognitive variables for BAOD patients. 


\section{Methods}

This case-control study was carried out at the Stroke Clinic of the Clinical Hospital of São Paulo University Medical School. The study protocol was approved by the Institutional Ethics Committee. All patients provided informed consent to participate.

2.1. Subjects. This study included 28 patients with ischemic stroke due to BAOD confirmed by computed tomography imaging or angiography, magnetic resonance (MR) imaging or angiography, and/or digital subtraction angiography. Cognitive assessment was performed at least 6 months after the stroke; at least 6 months had passed between the stroke and patient inclusion in the study. All patients had BAOD, defined as the presence of an infarct in the BA territory, and had $50 \%$ or greater stenosis or occlusion of the $\mathrm{BA}$, as diagnosed at the time of infarction.

Patients were matched by age and education level with 27 controls recruited from the São Paulo community. There were no statistically significant between-group differences (mean [standard deviation]) in age (patients: 66.5 [11.3] years, controls: 65.6 [7.8] years, $p=0.631$ ) or years of education (patients: 6.5 [5.1] years, controls: 6.4 [4.2] years; $p=0.868$ ).

Patients were excluded from the study if they (1) had other brain lesions such as tumors, hemorrhagic stroke, traumatic injury, epilepsy, or infectious disease, (2) had a current diagnosis of any psychiatric disorder, used alcohol or drugs, or were taking psychotropic or neuroleptic medications, (3) had a history of functional capacity impairment or complaints of cognitive deficits before the infarct that led to BAOD diagnosis, or (4) had a stroke in any other vascular territory (Figure 1). Healthy subjects were excluded if they (1) had any neurological or psychiatric disorder, (2) abused alcohol or drugs or were taking psychotropic medications, (3) had any motor, auditory, or visual disorder, (4) had lower-thanexpected scores for education level on the Mini-Mental State Exam (MMSE score $<20$ for illiterate individuals, $<25$ for $1-4$ years, $<26.5$ for $5-8$ years, $<28$ for $9-11$ years, and $<29$ for $\geq 12$ years of education $[13,14])$, (5) had an anxiety or depression score on the Hospital Anxiety and Depression Scale (HADS) of 9 or more [15], or (6) had a functional dependence score greater than 5 on the Pfeffer Functional Activities Questionnaire [16].

2.2. Clinical and Radiological Data. The following data were retrieved from medical charts and interviews with patients and their relatives: age, sex, years of education, comorbid conditions, vascular risk factors, infarct etiology, and clinical presentation. Brain and angiographic images of the patients were analyzed by an experienced neuroradiologist who was blinded to the clinical data and cognitive status of the patient. All patients had brain MR images. The neuroradiologist was asked to identify infarct location (cerebellum, brainstem, occipital lobe, thalamus, or other). BAOD was assessed by MR angiography and classified as mild (0-29\% stenosis), moderate (30-69\% stenosis), or severe (70-99\% stenosis or occlusion). Locations of stenoses or occlusions were recorded $[17,18]$.

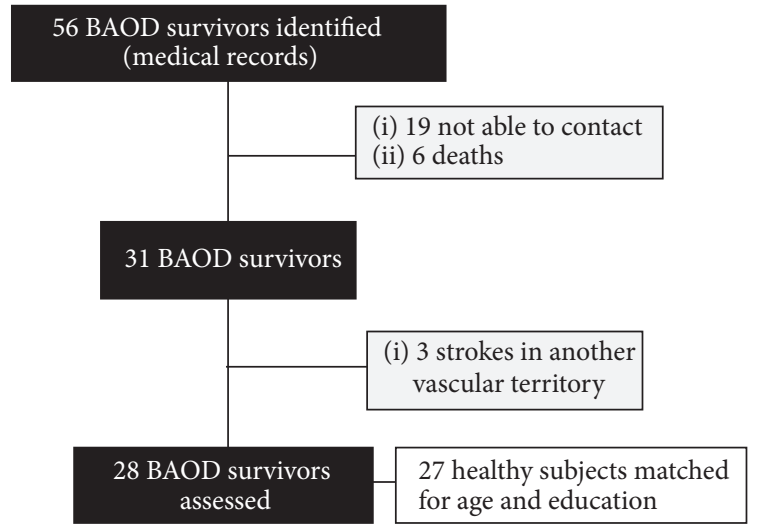

BAOD: basilar artery occlusion disease

FIGURE 1: Flowchart for recruiting BAOD survivors and healthy controls.

2.3. Neuropsychological Tests. Cognitive and functional outcomes were evaluated in a single interview by an experienced neuropsychologist. This contact occurred, on average, 6.7 years (minimum of 6 months) after the patient's first stroke. The MMSE $[13,14]$ and comprehensive cognitive assessment with neuropsychological tests were performed at this time. Rationale for inclusion of each test was based on previous literature showing that an extensive battery of cognitive tests demonstrates higher accuracy for identifying possible cognitive impairments in neurological patients [19].

The following neuropsychological tests were used to examine the corresponding cognitive domains: the Trail Making Test (TMT), Victoria version of the Stroop Test, Card 3 (Stroop Card 3) [20], and Symbol Digit Modalities Test (SDMT) [21] for attention and information processing speed; the Phonemic Verbal Fluency Task [22], Category Fluency Test (animals) [23], and Modified Wisconsin Card Sorting Test (MWCST) [24] for executive function; the Wechsler Adult Intelligence Scale-Digit Span [25] for shortterm memory; the Hopkins Verbal Learning Test-Revised (HVLT-R) [26] and Brief Visuospatial Memory Test-Revised (BVMT-R) [27] for long-term memory; the Boston Naming Test (BNT) [28] for language; and the Visual Object and Space Perception Battery: Fragmented Letters and Position Discrimination [29] for perceptive and visuospatial ability. All cognitive abilities and tests are listed in Table 1. Mood evaluation was carried out with the HADS [15].

Functional capacities of the survivors before the first stroke and at the moment of the present study were evaluated by the Modified Rankin Scale (mRS) [30]. This scale includes seven scores that describe the functional status of patients: 0 : no symptoms at all; 1 : no disability despite symptoms; 2 : slight disability; 3 : moderate disability; 4 : moderately severe disability; 5: severe disability; and 6: death.

2.4. Statistical Analysis. Absolute and relative frequencies as well as measures of central tendency and dispersion were used to present demographic, clinical, and radiological data. 
TABLE 1: Comparison of cognitive outcomes (raw score) between BAOD patients and healthy controls.

\begin{tabular}{|c|c|c|c|c|}
\hline Cognitive functions & Cognitive tests & $\begin{array}{c}\text { Patients } \\
\text { Mean (SD) }\end{array}$ & $\begin{array}{c}\text { Controls } \\
\text { Mean (SD) }\end{array}$ & $p$ \\
\hline \multicolumn{5}{|c|}{ Memory } \\
\hline Short-term memory & Digit Span & $10.0(2.52)$ & $10.85(2.73)$ & 0.208 \\
\hline \multirow{3}{*}{ Long-term memory (verbal episodic memory) } & HVLT-R immediate recall & $18.04(5.10)$ & $21.85(3.11)$ & $0.002^{* *}$ \\
\hline & HVLT-R delayed recall & $5.04(2.85)$ & $6.81(1.78)$ & $0.008^{* *}$ \\
\hline & HVLT-R recognition & $8.86(2.22)$ & $10.00(1.11)$ & $0.048^{*}$ \\
\hline \multirow{3}{*}{ Long-term memory (visuospatial episodic memory) } & BVMT-R immediate recall & $14.78(10.11)$ & $19.59(6.52)$ & $0.043^{*}$ \\
\hline & BVMT-R delayed recall & $5.59(4.05)$ & $7.67(2.90)$ & $0.035^{*}$ \\
\hline & BVMT-R recognition & $4.85(1.35)$ & $5.70(0.54)$ & $0.015^{*}$ \\
\hline \multicolumn{5}{|c|}{ Language } \\
\hline Naming & BNT & $43.89(8.77)$ & $48.48(5.21)$ & $0.048^{*}$ \\
\hline \multicolumn{5}{|c|}{ Executive function } \\
\hline \multirow{2}{*}{ Monitoring rules } & Phonemic Verbal Fluency & $23.73(10.67)$ & $26.62(8.09)$ & 0.277 \\
\hline & Category Fluency & $12.11(4.43)$ & $13.59(2.62)$ & 0.095 \\
\hline Mental flexibility & MWCST & $3.29(1.8)$ & $4.48(1.50)$ & $0.013^{*}$ \\
\hline \multicolumn{5}{|c|}{ Perceptive and visuospatial ability } \\
\hline Perceptive ability & Fragmented Letters & $18.52(2.08)$ & $19.15(0.93)$ & 0.645 \\
\hline Visuospatial ability & Position Discrimination & $18.14(1.94)$ & $19.59(0.75)$ & $0.002^{* *}$ \\
\hline \multicolumn{5}{|c|}{ Attention and processing speed } \\
\hline Processing speed & SDMT & $18.14(12.10)$ & $28.26(10.57)$ & $0.001^{* *}$ \\
\hline Sustained attention & TMT Part A & $70.61(55.26)$ & $50.85(20.28)$ & 0.152 \\
\hline Set-shifting attention & TMT Part B & $202.13(86.95)$ & $135.27(48.08)$ & $0.013^{*}$ \\
\hline Selective attention & Stroop C & $49.00(22.34)$ & $33.58(7.29)$ & $0.001^{* *}$ \\
\hline Cognitive screening & MMSE & $25.09(3.68)$ & $27.44(1.45)$ & $0.018^{*}$ \\
\hline
\end{tabular}

Note. $*$ indicates $p<0.05$ and $* *$ indicate $p<0.01$. Digit Span: number of correct responses of forward plus backward order; HVLT-R and BVMT-R: immediate recall (sum of 3 immediate recall trials), delayed recall (sum of words or figures with form and location correct), and recognition (correct hits minus false-positive responses); BNT: hits without prompts plus hits after semantic prompts; MWCST: total number of categories; Phonemic Verbal Fluency Task: sum of words beginning with F + A + S; Category Fluency Test: sum of animal names; Fragmented Letters and Position Discrimination: sum of correct responses; SDMT: sum of correct responses; TMT Parts A and B: time in seconds; Stoop C: time in seconds; and MMSE: sum of correct responses.

Means are followed by standard deviations in parentheses. Distributions of the data were examined by the Shapiro-Wilk normality test. Comparisons of raw scores between groups were conducted by the Mann-Whitney test for nonnormally distributed variables or by one-way ANOVA otherwise. Other comparisons were conducted with the $z$-score for cognitive variables from the appropriate normative data. When analysis of covariance was necessary, the ANCOVA test was used. Effect size was calculated with eta squared. Correlations were measured with the Spearman or Pearson correlation coefficient. A $p$ value less than 0.05 was considered statistically significant.

\section{Results}

All patients had vascular risk factors, with an average of 4.6 (1.5) factors per patient. Hypertension was present in all patients. Lesions were detected in the brainstem or cerebellum in more than two-thirds of patients. The proximal BA was the most commonly affected segment by arterial stenosis or occlusion. Radiological characteristics are shown in Table 2.
Table 1 shows raw score comparisons of cognitive performance between patients and controls. There were significant differences between patients and controls in the HVLT-R and BVMT-R (immediate and delayed recall and recognition), BNT, MWCST, Position Discrimination, SDMT, TMT Part B, Stroop Card 3, and MMSE results.

Table 3 shows $z$-score comparisons of cognitive performance between patients and controls, while controlling for age and education between groups. There were significant differences between patients and controls in the HVLT$\mathrm{R}$ (immediate and delayed recall), BVMT-R (immediate and delayed recall and recognition), Category Fluency Test, MWCST, Position Discrimination, SDMT, TMT Parts A and $B$, and Stroop Card 3 results. However, the effect sizes were small. $z$-score values for patients were negative but did not indicate severe cognitive impairment.

Six patients had relevant mood alterations or symptoms of depression, and six patients had symptoms of anxiety as assessed by the HADS. Pearson correlations indicated that anxiety symptoms were moderately and negatively related to HVLT-R recognition. Anxiety and depression had 
TABLE 2: Clinical characteristics of BAOD survivors.

\begin{tabular}{|c|c|c|}
\hline Risk Factors & $N(28)$ & $\%$ \\
\hline Hypertension & 28 & $100 \%$ \\
\hline Dyslipidemia & 22 & $79 \%$ \\
\hline Transient ischemic attack & 13 & $46 \%$ \\
\hline Diabetes mellitus & 13 & $46 \%$ \\
\hline Smoking & 12 & $43 \%$ \\
\hline Obesity & 6 & $21 \%$ \\
\hline Heart disease & 10 & $36 \%$ \\
\hline Prior stroke & 10 & $36 \%$ \\
\hline Alcoholism & 6 & $21 \%$ \\
\hline Migraine & 4 & $14 \%$ \\
\hline Family history of stroke & 5 & $18 \%$ \\
\hline Contraceptive use & 1 & $4 \%$ \\
\hline Lesion location & $N(28)$ & $\%$ \\
\hline Cerebellum & 20 & $71 \%$ \\
\hline Brainstem & 19 & $68 \%$ \\
\hline Occipital & 11 & $39 \%$ \\
\hline Thalamus & 10 & $36 \%$ \\
\hline Stenosis location & $N(28)$ & $\%$ \\
\hline Proximal & 20 & $71 \%$ \\
\hline Medial & 11 & $39 \%$ \\
\hline Distal & 8 & $29 \%$ \\
\hline Multiple & 8 & $29 \%$ \\
\hline Severity of stenosis & $N(28)$ & $\%$ \\
\hline Mild & 7 & $25 \%$ \\
\hline Moderate & 8 & $29 \%$ \\
\hline Severe & 10 & $36 \%$ \\
\hline Occlusion & 3 & $11 \%$ \\
\hline Mood & $N(28)$ & $\%$ \\
\hline Depression & 6 & $22 \%$ \\
\hline Anxiety & 6 & $22 \%$ \\
\hline
\end{tabular}

a moderate positive relationship with BVMT-R immediate recall (Table 4).

Before experiencing a stroke, none of the survivors had significant functional dependence. At the time when they were evaluated (6.7 [5.1] years after stroke), all patients had mRS scores of 3 or less; specifically, 5 patients (18\%) had a score of 3, 2 patients (7\%) had a score of 2,13 patients (46\%) had a score of 1 , and 8 patients (29\%) had a score of 0 . Therefore, $75 \%$ of patients had no functional disability, and $25 \%$ had slight to moderate functional disability.

Spearman correlations between cognitive outcomes and mRS results are presented in Table 4. In univariate analyses, significant correlations were present between $\mathrm{mRS}$ scores and all cognitive test results, except for Digit Span, Phonemic Verbal Fluency, and Fragmented Letters. Correlation coefficients indicated a generally moderate relationship among variables, although the relationship was weak for Category Fluency and strong for SDMT.

\section{Discussion}

Compared to controls, BAOD survivors presented with impairments in selective, sustained, and set-shifting attention, processing speed, visuospatial skills, mental flexibility, and monitoring rules. There were significant deficits in verbal episodic memory (immediate and delayed recall) and visuospatial episodic memory (immediate and delayed recall and recognition). Mild to moderate correlations were found between performance on some cognitive tests and functional capacity scales.

Infarcts in the BA territory are commonly located in the thalamus, brainstem, and cerebellum. Patients with lesions in these territories, not specifically caused by BAOD, exhibit similar impairments in performance on neuropsychological testing $[4,5,11,31]$. Patients with posterior circulation infarcts have impairments in executive function, attention, memory [6], visuospatial ability $[6,7]$, and language $[6,8]$. These cognitive profiles have been attributed to damage in the neural networks that link anterior with brainstem and cerebellar regions $[4,5]$.

Encephalic regions within the BA territory are connected via the thalamus [31-33] with the parietal [34-36] and frontal cortices $[4,5]$. These connections have been associated with top-down and bottom-up information processing systems related to executive monitoring, as well as attentional and perceptual systems $[4,5,37]$. It is possible that lesions in these regions (in our sample, due to BAOD) contributed to the observed cognitive test results.

Functional capacity was moderately correlated with the presence of cognitive impairment, indicating that worse functional results were due to poorer scores on cognitive tests. However, $75 \%$ of patients in this study had good mRS results, suggesting favorable functional outcomes for the BAOD survivors. In a previous study, patients with vertebrobasilar territory lesions had better functional outcomes on the mRS compared to patients with lesions in the internal carotid artery territory [38]. Another study reported a good functional prognosis at the 1-year follow-up [11], which is in line with our findings.

Our results can be explained by the small patient $z$-score values for outcomes other than SDMT, Position Discrimination, and TMT B. This finding indicates that cognitive deficits were not important, despite the statistically significant differences compared to controls. This discrepancy could be due to the small effect size.

Symptoms of anxiety and depression are frequently reported after cerebrovascular disease [39]. Even in the absence of neurological deficits, their presence is predominantly related to memory and attention deficits $[40,41]$. However, in our group of patients, the frequency of anxiety or depression symptoms was relatively low. Anxiety symptoms showed a negative relationship with one long-term verbal memory variable, and the anxiety and depression symptoms were positively related to one long-term visuospatial memory variable. These conflicting results could be due to the exclusion of patients with a history of psychiatric disorders or who were currently using psychotropic medications. The low 
TABLE 3: Comparison of cognitive outcomes ( $z$-scores) between BAOD patients and healthy controls.

\begin{tabular}{|c|c|c|c|c|}
\hline Cognitive tests & $\begin{array}{c}\text { Patients } \\
\text { Mean (SD) }\end{array}$ & $\begin{array}{c}\text { Controls } \\
\text { Mean (SD) }\end{array}$ & $p$ & Effect size \\
\hline Digit Span & $-0.10(0.82)$ & $0.06(0.68)$ & 0.417 & 0.013 \\
\hline HVLT-R immediate recall & $-0.47(0.88)$ & $0.19(0.61)$ & $0.002^{* *}$ & 0.178 \\
\hline HVLT-R delayed recall & $-0.91(1.12)$ & $-0.09(0.76)$ & $0.003^{* *}$ & 0.159 \\
\hline HVLT-R recognition & $-0.58(1.38)$ & $-0.03(0.72)$ & 0.055 & 0.070 \\
\hline BVMT-R immediate recall & $-0.29(1.25)$ & $0.39(0.71)$ & $0.018^{*}$ & 0.106 \\
\hline BVMT-R delayed recall & $-0.47(1.18)$ & $0.25(0.78)$ & $0.012^{*}$ & 0.117 \\
\hline BVMT-R recognition & $-0.33(1.28)$ & $0.43(0.47)$ & $0.005^{* *}$ & 0.146 \\
\hline BNT & $0.61(1.21)$ & $1.07(0.79)$ & 0.061 & 0.067 \\
\hline Phonemic Verbal Fluency & $-0.46(1.07)$ & $-0.12(0.91)$ & 0.227 & 0.030 \\
\hline Category Fluency & $-0.53(0.97)$ & $-0.02(0.73)$ & $0.036^{*}$ & 0.083 \\
\hline MWCST & $-1.01(1.17)$ & $-0.18(0.84)$ & $0.002^{* *}$ & 0.181 \\
\hline Fragmented Letters & $-0.90(2.08)$ & $-0.25(0.92)$ & 0.137 & 0.046 \\
\hline Position Discrimination & $-1.93(2.42)$ & $-0.13(0.94)$ & $0.001^{* *}$ & 0.198 \\
\hline SDMT & $-2.24(1.24)$ & $-1.21(1.11)$ & $0.001^{* *}$ & 0.204 \\
\hline TMT Part A & $-1.27(2.79)$ & $0.25(1.38)$ & $0.015^{*}$ & 0.120 \\
\hline TMT Part B & $-1.76(2.36)$ & $-0.08(1.00)$ & $0.002^{* *}$ & 0.202 \\
\hline Stroop C & $-0.66(1.76)$ & $0.68(0.72)$ & $0.001^{* *}$ & 0.212 \\
\hline
\end{tabular}

Note. $*$ indicates $p<0.05$ and $* *$ indicate $p<0.01$. Controls were matched with patients for age and education level.

TABLE 4: Correlations among cognitive variables ( $z$-scores), anxiety and depression symptoms, and functional capacity variables.

\begin{tabular}{|c|c|c|c|c|c|c|}
\hline \multirow{2}{*}{ Cognitive tests } & \multicolumn{2}{|c|}{$\mathrm{mRS}$} & \multicolumn{2}{|c|}{ Anxiety symptoms } & \multicolumn{2}{|c|}{ Depression symptoms } \\
\hline & $r$ & $p$ & $r$ & $p$ & $r$ & $p$ \\
\hline Digit Span & -0.222 & 0.103 & -0.210 & 0.292 & -0.037 & 0.854 \\
\hline HVLT-R immediate recall & $-0.526^{* *}$ & $<0.001$ & -0.194 & 0.333 & -0.136 & 0.498 \\
\hline HVLT-R delayed recall & $-0.467^{* *}$ & $<0.001$ & 0.037 & 0.855 & 0.089 & 0.659 \\
\hline HVLT-R recognition & $-0.476^{* *}$ & $<0.001$ & $-0.410^{*}$ & 0.034 & -0.282 & 0.153 \\
\hline BVMT-R immediate recall & $-0.542^{* *}$ & $<0.001$ & $0.399^{*}$ & 0.044 & $0.527^{* *}$ & 0.006 \\
\hline BVMT-R delayed recall & $-0.524^{* *}$ & $<0.001$ & 0.148 & 0.462 & 0.370 & 0.058 \\
\hline BVMT-R recognition & $-0.465^{* *}$ & $<0.001$ & 0.012 & 0.953 & 0.242 & 0.233 \\
\hline $\mathrm{BNT}$ & $-0.423^{* *}$ & 0.001 & -0.124 & 0.538 & 0.096 & 0.634 \\
\hline Phonemic Verbal Fluency & -0.237 & 0.091 & -0.272 & 0.189 & 0.011 & 0.960 \\
\hline Category Fluency & $-0.325^{*}$ & 0.016 & -0.081 & 0.689 & 0.048 & 0.810 \\
\hline MWCST & $-0.565^{* *}$ & $<0.001$ & 0.172 & 0.392 & 0.223 & 0.263 \\
\hline Fragmented Letters & -0.067 & 0.640 & $-0.421^{*}$ & 0.040 & -0.296 & 0.161 \\
\hline Position Discrimination & $-0.570^{* *}$ & $<0.001$ & -0.012 & 0.952 & -0.002 & 0.993 \\
\hline SDMT & $-0.679^{* *}$ & $<0.001$ & -0.063 & 0.755 & 0.093 & 0.644 \\
\hline TMT Part A & $0.598^{* *}$ & $<0.001$ & 0.138 & 0.521 & 0.150 & 0.484 \\
\hline TMT Part B & $0.599^{* *}$ & $<0.001$ & 0.114 & 0.603 & 0.241 & 0.269 \\
\hline Stroop Card 3 & $0.568^{* *}$ & $<0.001$ & 0.106 & 0.631 & 0.012 & 0.956 \\
\hline
\end{tabular}

Note. $*$ indicates $p<0.05$ and $* *$ indicate $p<0.01$. 
number of patients with such symptoms may have led to a floor effect for correlations with cognitive impairments.

A limitation of the present study was the relatively small sample size, which should be rectified by future investigations. Nevertheless, to our knowledge, this is the first study to investigate the long-term cognitive profiles of BAOD survivors.

\section{Conclusion}

Our sample of BAOD survivors showed impairments in episodic memory, visuospatial skills, executive function, and attention (mental flexibility, monitoring rules, and processing speed, as well as selective, sustained, and set-shifting attention). Functional capacity outcomes were significantly related to the cognitive test results. Overall, our results indicate good functional outcomes in a selected group of BAOD survivors, despite the presence of subnormal performance on some cognitive tests.

\section{Conflict of Interests}

The authors declare that there is no conflict of interests regarding the publication of this paper.

\section{References}

[1] S. D. Israeli-Korn, Y. Schwammenthal, T. Yonash-Kimchi et al., "Ischemic stroke due to acute basilar artery occlusion: proportion and outcomes," Israel Medical Association Journal, vol. 12, no. 11, pp. 671-675, 2010.

[2] C. G. Weimar, M. Goertler, L. Harms, and H.-C. Diener, "Distribution and outcome of symptomatic stenoses and occlusions in patients with acute cerebral ischemia," Archives of Neurology, vol. 63, no. 9, pp. 1287-1291, 2006.

[3] P. B. Garrard, D. Bradshaw, H. R. Jäger, A. J. Thompson, N. Losseff, and D. Playford, "Cognitive dysfunction after isolated brain stem insult. An underdiagnosed cause of long term morbidity," Journal of Neurology Neurosurgery and Psychiatry, vol. 73, no. 2, pp. 191-194, 2002.

[4] M. Hoffmann and F. Schmitt, "Cognitive impairment in isolated subtentorial stroke," Acta Neurologica Scandinavica, vol. 109, no. 1, pp. 14-24, 2004.

[5] M. Hoffmann and L. B. Cases, "Etiology of frontal network syndromes in isolated subtentorial stroke," Behavioural Neurology, vol. 20, no. 3-4, pp. 101-105, 2008.

[6] K.-Y. Park, S.-S. Yoon, and H.-Y. Rhee, "Executive dysfunction associated with stroke in the posterior cerebral artery territory," Journal of Clinical Neuroscience, vol. 18, no. 2, pp. 203-208, 2010.

[7] O. Martinaud, D. Pouliquen, E. Gérardin et al., "Visual agnosia and posterior cerebral artery infarcts: an anatomical-clinical study," PLoS ONE, vol. 7, no. 1, Article ID e30433, 2012.

[8] E. Capitani, M. Laiacona, R. Pagani, R. Capasso, P. Zampetti, and G. Miceli, "Posterior cerebral artery infarcts and semantic category dissociations: a study of 28 patients," Brain, vol. 132, no. 4, pp. 965-981, 2009.

[9] J. G. M. Ciríaco, C. D. C. Leite, M. D. Martin et al., "Basilar artery occlusive disease in stroke survivors in a multiethnic population," Clinical Neurology and Neurosurgery, vol. 112, no. 3, pp. 233-236, 2010.
[10] T. H. Glass, P. M. Hennessey, L. Pazdera et al., "Outcome at 30 days in the New England Medical Center Posterior Circulation Registry," Archives of Neurology, vol. 59, no. 3, pp. 369-376, 2002.

[11] Y. Ju, M. Hussain, K. Asmaro et al., "Clinical and imaging characteristics of isolated pontine infarcts: a one-year follow-up study," Neurological Research, vol. 35, no. 5, pp. 498-504, 2013.

[12] C. Ottomeyer, J. Zeller, G. Fesl et al., "Multimodal recanalization therapy in acute basilar artery occlusion: long-term functional outcome and quality of life," Stroke, vol. 43, no. 8, pp. 2130-2135, 2012.

[13] S. M. Brucki, R. Nitrini, P. Caramelli, P. H. Bertolucci, and I. H. Okamoto, "Sugestões para o uso do mini-exame do estado mental no Brasil," Arquivos de Neuro-Psiquiatria, vol. 61, no. 3, pp. 777-781, 2003.

[14] M. F. Folstein, S. E. Folstein, and P. R. McHugh, "Mini-mental state. A practical method for grading the cognitive state of patients for the clinician," Journal of Psychiatric Research, vol. 12, no. 3, pp. 189-198, 1975.

[15] A. S. Zigmond and R. P. Snaith, "The hospital anxiety and depression scale," Acta Psychiatrica Scandinavica, vol. 67, no. 6, pp. 361-370, 1983.

[16] R. K. Pfeffer, T. T. Kurosaki, C. H. Harrah Jr., J. M. Chance, and S. Filos, "Measurement of functional activities in older adults in the community," The Journals of Gerontology, vol. 37, no. 3, pp. 323-329, 1982.

[17] H. J. M. Barnett, D. W. Taylor, M. Eliasziw et al., "Benefit of carotid endarterectomy in patients with symptomatic moderate or severe stenosis," The New England Journal of Medicine, vol. 339, no. 20, pp. 1415-1425, 1998.

[18] European Carotid Surgery Trialists' Collaborative Group, "Endarterectomy for moderate symptomatic carotid stenosis: interim results from the MRC European Carotid Surgery Trial," The Lancet, vol. 347, no. 9015, pp. 1591-1593, 1996.

[19] E. C. Miotto, F. Z. Cinalli, V. T. Serrao, G. G. Benute, M. C. S. Lucia, and M. Scaff, "Cognitive deficits in patients with mild to moderate traumatic brain injury," Arquivos de Neuro-Psiquiatria, vol. 68, no. 6, pp. 862-868, 2010.

[20] K. R. Campanholo, M. A. Romão, M. A. R. Machado et al., "Performance of an adult Brazilian sample on the trail making test and stroop test," Dementia e Neuropsychologia, vol. 8, no. 1, pp. 26-31, 2014.

[21] A. Smith, Symbol Digit Modalities Test-Manual, University of Michigan, Los Angeles, Calif, USA, 9th edition, 2002.

[22] T. H. Machado, H. C. Fichman, E. L. Santos et al., "Normative data for healthy elderly on the phonemic verbal fluency taskFAS," Dementia e Neuropsychologia, vol. 3, no. 1, pp. 55-60, 2009.

[23] S. M. D. Brucki and M. S. G. Rocha, "Category fluency test: effects of age, gender and education on total scores, clustering and switching in Brazilian Portuguese-speaking subjects," Brazilian Journal of Medical and Biological Research, vol. 37, no. 12, pp. 1771-1777, 2004.

[24] H. E. Nelson, "A modified card sorting test sensitive to frontal lobe deficits," Cortex, vol. 12, no. 4, pp. 313-324, 1976.

[25] E. Nascimento, Escala de Inteligência Wechsler para Adultos: Manual David Weschsler, translated by M. C. D. V. M. Silva, Casa do Psicólogo, São Paulo, Brazil, 1st edition, 2004.

[26] J. B. Brandt and R. H. B. Benedict, Hopkins Verbal Learning Test-Revised, Psychological Assessment Resources, Odessa, Fla, USA, 2001.

[27] R. Benedict, Brief Visuospatial Memory Test-Revised, Psychological Assessment Resources, Odessa, Fla, USA, 1997. 
[28] E. C. Miotto, J. Sato, M. C. S. Lucia, C. H. P. Camargo, and M. Scaff, "Development of an adapted version of the Boston Naming Test for Portuguese speakers," Revista Brasileira de Psiquiatria, vol. 32, no. 3, pp. 279-282, 2010.

[29] E. M. Caparelli-Dáquer, A. C. Manhães, and A. L. Schmidt, VOSP Bateria de Percepção Visual de Objetos e de Espaço: MANUAL Versão Traduzida e Adaptada para o Português-Padronização Versão Brasileira, Cognição, Rio de Janeiro, Brazil, 1999.

[30] J. T. L. Wilson, A. Hareendran, A. Hendry, J. Potter, I. Bone, and K. W. Muir, "Reliability of the modified Rankin Scale across multiple raters," Stroke, vol. 36, no. 4, pp. 777-781, 2005.

[31] W. H. Li, T. Han, W. Qin et al., "Altered functional connectivity of cognitive-related cerebellar subregions in well-recovered stroke patients," Neural Plasticity, vol. 2013, Article ID 452439, 10 pages, 2013.

[32] N. R. Graff-Radford, H. Damasio, T. Yamada, and P. J. Eslinger, "Nonhaemorrhagic thalamic infarction. Clinical, neuropsychological and electrophysiological findings in four anatomical groups defined by computerized tomography," Brain, vol. 108, no. 2, pp. 485-516, 1985.

[33] M. Glickstein and K. Doron, "Cerebellum: connections and functions," Cerebellum, vol. 7, no. 4, pp. 589-594, 2008.

[34] M. P. Molinari, L. Petrosini, S. Misciagna, and M. G. Leggio, "Visuospatial abilities in cerebellar disorders," Journal of Neurology, Neurosurgery \& Psychiatry, vol. 75, no. 2, pp. 235-240, 2004, http://www.ncbi.nlm.nih.gov/pmc/articles/PMC1738892/pdf/ v075p00235.pdf.

[35] C. J. Stoodley, E. M. Valera, and J. D. Schmahmann, "An fMRI study of intra-individual functional topography in the human cerebellum," Behavioural Neurology, vol. 23, no. 1-2, pp. 65-79, 2010.

[36] C. J. Stoodley, "The cerebellum and cognition: evidence from functional imaging studies," Cerebellum, vol. 11, no. 2, pp. 352365, 2012.

[37] J. A. Kipping, W. Grodd, V. Kumar, M. Taubert, A. Villringer, and D. S. Margulies, "Overlapping and parallel cerebello-cerebral networks contributing to sensorimotor control: an intrinsic functional connectivity study," NeuroImage, vol. 83, pp. 837$848,2013$.

[38] Y. S. Ng, J. Stein, M. Ning, and R. M. Black-Schaffer, "Comparison of clinical characteristics and functional outcomes of ischemic stroke in different vascular territories," Stroke, vol. 38, no. 8, pp. 2309-2314, 2007.

[39] L. A. Terroni, E. Amaro Jr., D. V. Iosifescu et al., "Stroke lesion in cortical neural circuits and post-stroke incidence of major depressive episode: a 4-month prospective study," The World Journal of Biological Psychiatry, vol. 12, no. 7, pp. 539-548, 2011.

[40] C. L. Marvel and S. Paradiso, "Cognitive and neurological impairment in mood disorders," Psychiatric Clinics of North America, vol. 27, no. 1, pp. 19-36, 2004.

[41] J. B. Godard, P. Baruch, S. Grondin, and M. F. Lafleur, "Psychosocial and neurocognitive functioning in unipolar and bipolar depression: a 12-month prospective study," Psychiatry Research, vol. 196, no. 1, pp. 145-153, 2012. 


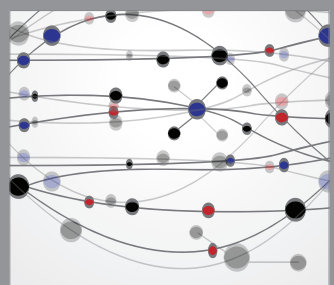

The Scientific World Journal
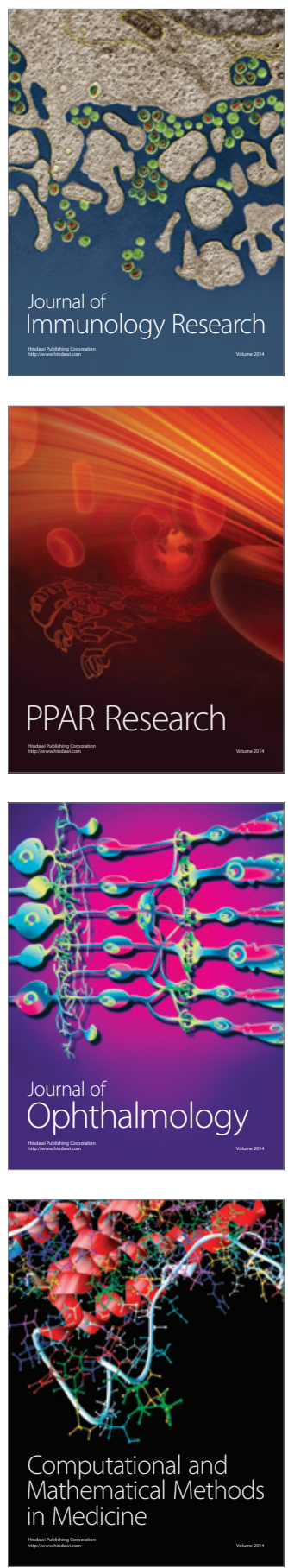

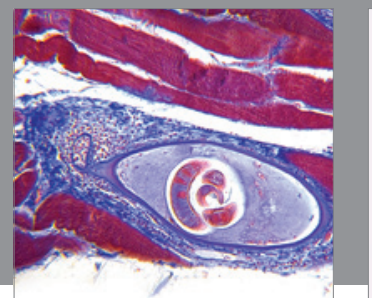

Gastroenterology

Research and Practice
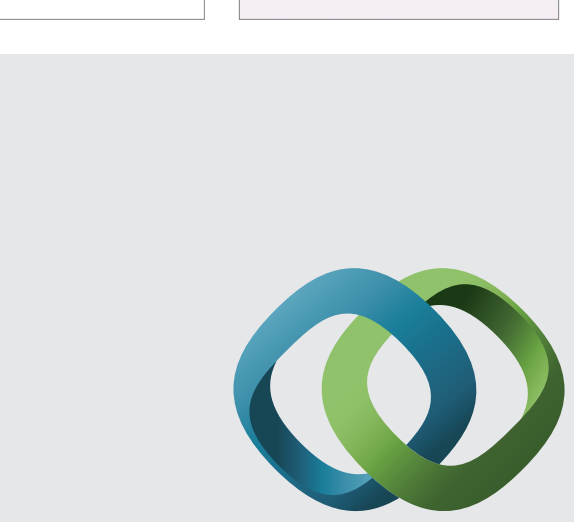

\section{Hindawi}

Submit your manuscripts at

http://www.hindawi.com
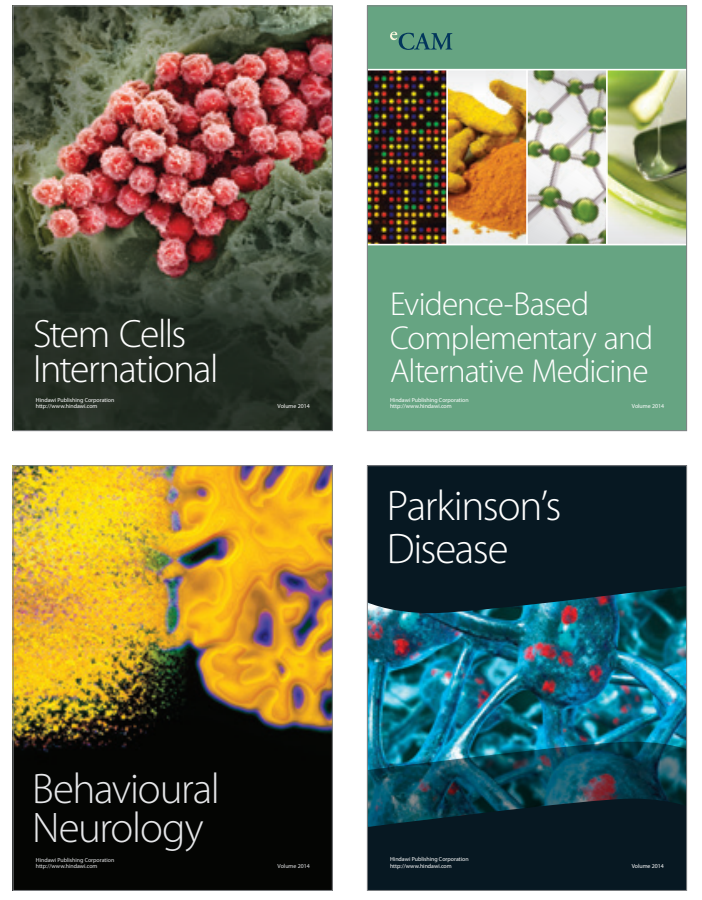
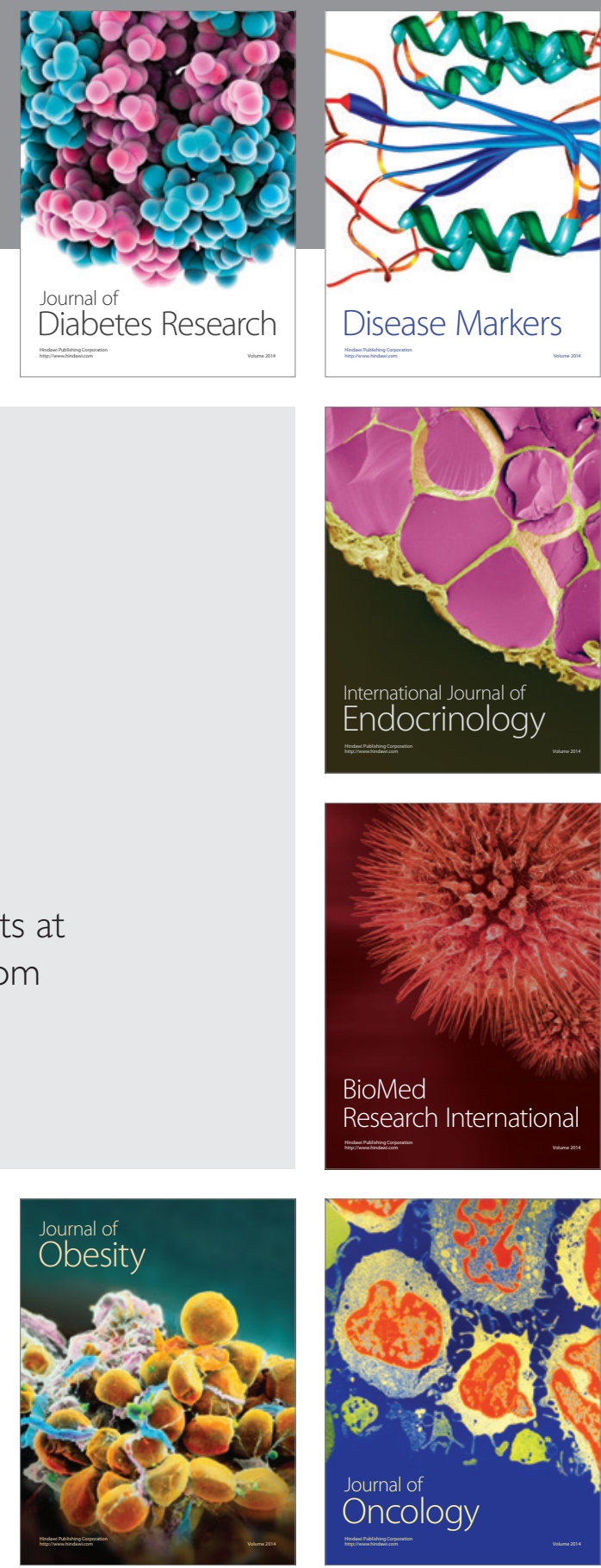

Disease Markers
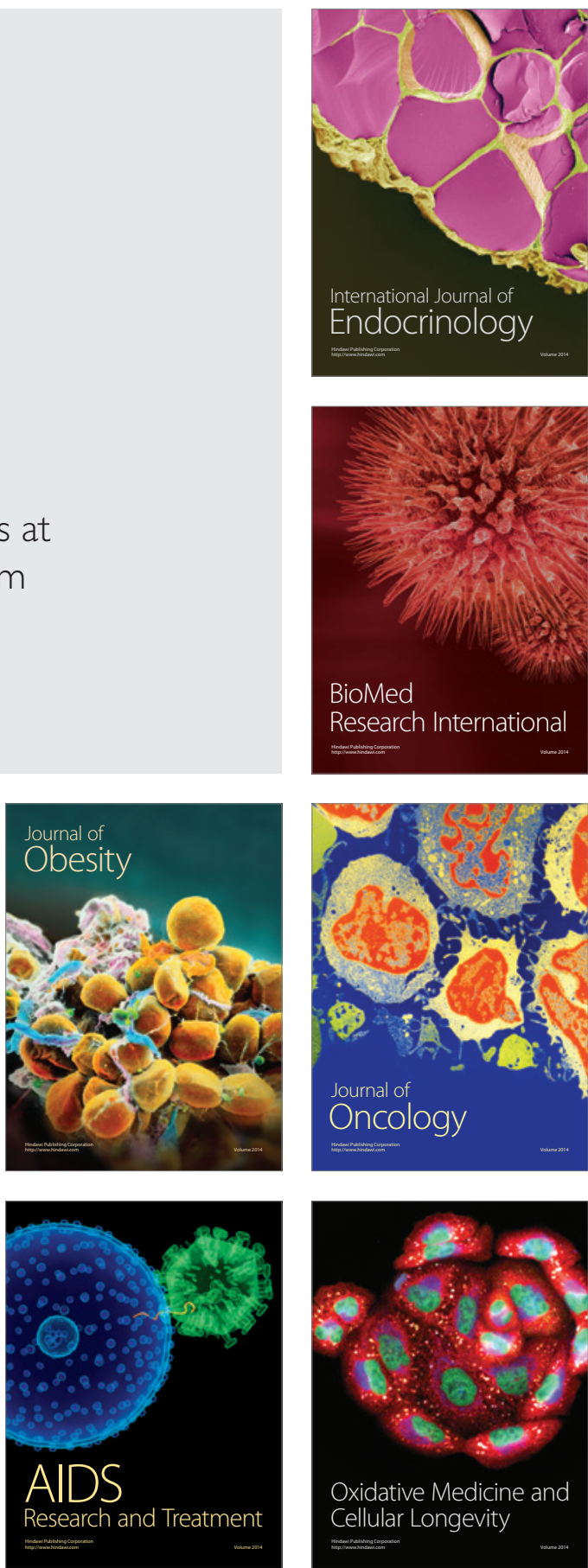